\title{
Correction to: Conservation developmental process in early childhood: Impact of intrinsic motivation and practice effects
}

\section{Nobuki Watanabe ${ }^{1}$}

Published online: 6 February 2021

(C) Springer Science+Business Media, LLC, part of Springer Nature 2021

\section{Correction to: Curr Psychol (2020)} https://doi.org/10.1007/s12144-020-01217-x

The original version of this article unfortunately contained a mistake in Table 3. Thus, this erratum is presented to fix the error, providing the correct Table 3.

Table 3 Difference between the number of correct and incorrect answers in both the first and last trials of first, second, and third grades

\begin{tabular}{lllll}
\hline First Grade & Trial $(n=30)$ & \multicolumn{2}{c}{$\chi^{2}$} & $p$ \\
& First & Last & & \\
Pass & 0 & 1 & 1.017 & 0.313244 \\
Fail & 30 & 29 & & \\
Second Grade & Trial $(n=32)$ & & $\chi^{2}$ & $p$ \\
& First & Last & & \\
Pass & 0 & 3 & 3.148 & $0.076041^{\dagger}$ \\
Fail & 32 & 29 & & \\
Third Grade & Trial $(n=24)$ & & $\chi^{2}$ & $p$ \\
& First & Last & & \\
Pass & 2 & 9 & 5.779 & $0.01622^{*}$ \\
Fail & 22 & 15 & & \\
\hline
\end{tabular}

Results of $\chi$-square test for the difference between the number of correct and incorrect answers in each trial $(p<.05,<.10 ; \chi$-square $)$

${ }^{\dagger} p<.10, * p<.05$
The original article has been corrected.

Publisher's Note Springer Nature remains neutral with regard to jurisdictional claims in published maps and institutional affiliations.

The online version of the original article can be found at https://doi.org/ 10.1007/s12144-020-01217-x

Nobuki Watanabe

nobuki@kwansei.ac.jp

1 School of Education, Kwansei Gakuin University, 7-54, Okadayama, Nishinomiya, Hyogo 662-0827, Japan 